Language and Cognition 13 (2021), 161-190. doi:10.1017/langcog.2020.31

(C) The Author(s), 2020. Published by Cambridge University Press on behalf of UK Cognitive Linguistics Association. This is an Open Access article, distributed under the terms of the Creative Commons Attribution licence (http://creativecommons.org/licenses/by/4.0/), which permits unrestricted re-use, distribution, and reproduction in any medium, provided the original work is properly cited.

\title{
Directional prepositions and event endpoint conceptualization: a study of naar and richting in Dutch*
}

YIYUN LIAO

KATINKA DIJKSTRA

A N D

ROLF A. ZWAAN

Department of Psychology, Education and Child Studies, Erasmus University Rotterdam, the Netherlands

(Received 20 November 2019 - Revised 10 September 2020 - Accepted 10 September 2020 First published online 15 October 2020)

\section{A B S T R A C T}

Two Dutch directional prepositions (i.e., naar and richting) provide a useful paradigm to study endpoint conceptualization. Experiment 1 adopted a sentence comprehension task and confirmed the linguistic proposal that, when naar was used in motion event descriptions, participants were more certain that the reference object was the goal of the agent than when richting was used. Experiment 2 and Experiment 3 used this linguistic pair to test the effect of two factors (i.e., the actor's goal and the interlocutor's status) on endpoint conceptualization via language production tasks. We found significant effects of both factors. First, participants chose naar more often when there was an inference in the referential situation that the reference object was the actor's goal than when there was no such inference. Second, participants chose richting more often when they were told to describe the referential scenario to a police officer than to a friend. Participants were more cautious with their statements and

[*] This work was supported by China Scholarship Council: [grant number 201606020119]; National Social Science Fund of China: [grant number 18CYY004]. We would like to thank all anonymous reviewers for their useful comments and suggestions on the earlier drafts of this manuscript. Address for correspondence: Yiyun Liao, Erasmus University Rotterdam, P.O. Box 1738, 3000 DR Rotterdam, The Netherlands. e-mail: liao@essb.eur. nl. 
were less willing to commit themselves to stating the goal of the agent when talking to a police officer than to a friend. The results are discussed in relation to relevant linguistic theories and event theories.

KEYWORDS: event endpoint conceptualization, directional prepositions, the actor's goal, the interlocutor's status

\section{Introduction}

Events are an important topic in the fields of cognitive psychology and linguistics. Much of the research on event cognition is embedded in the context of language comprehension studies. This is because language is a major way of presenting and talking about events in our daily life. Moreover, it is much easier to construct events and manipulate the spatial and temporal relations among those events in language than in the real world (Radvansky \& Zacks, 2014). Researchers have proposed that language comprehension is conceptualized as the construction of a coherent event model or situation model. Situation models are mental representations of a state of affairs described in texts. Linguistic cues on both spatial and temporal relations among events described in texts contribute to the construction of situation models to achieve successful event comprehension (Johnson-Laird, 1983; van Dijk \& Kintsch, 1983; Zwaan, 2016; Zwaan \& Radvansky, 1998).

In event cognition studies, there is an increasing focus on event segmentation, given that segmenting meaningful discrete events (e.g., shopping) from a continuous flow of experience (e.g., walking around in a store, taking things from the shelf, bringing them to the counter, etc.) is key to effective memorization and learning. Being able to perceive and detect event boundaries is fundamental to segmenting events (Zacks \& Swallow, 2007). Changes that happen in space (e.g., entering a store) or in time (e.g., an egg got cooked) can both be considered as important clues that we use to perceive and define event boundaries. In language, we can easily present such changes by using spatial or temporal related expressions, which function as event-segmentation cues to the comprehender. One of the most studied linguistic cues of this type is grammatical aspect (Anderson, Matlock, \& Spivey, 2013; Becker, Ferretti, \& Madden-Lombardi, 2013; Madden \& Zwaan, 2003; Magliano \& Schleich, 2000; Matlock, 2011).

Grammatical aspect is the morphosyntactic marking of verbs that provide different viewpoints on the internal temporal structure of an event (e.g., beginning/ongoing/completed; Comrie, 1976; Declerck, 2007). A broad aspectual distinction is between imperfective and perfective aspect. The use of imperfective aspect in event descriptions directs the comprehender's attention to the internal temporal structure of an event (most often, the progression of an event), while the endpoint is defocused (e.g., he is cutting a carrot). In contrast, 
perfective aspect does not convey information on the internal structure of an event. It gives rise to a completed construct of an event and hence the attention is led to the end-state of the event (e.g., he cut a carrot) (Madden \& Zwaan, 2003).

Knowing the actor's goal of performing an action is also key to event boundary conceptualization. If the actor's goal is clear, it is then easy for the comprehender to combine relevant actions into a whole event (e.g., Graesser, Singer, \& Trabasso, 1994). Take cooking a meal as an example. Cooking a meal is composed of actions such as cutting vegetables and meat, stirring them in a pan, and finally serving them in a bowl. Given that we as a comprehender know that the actor's goal is to cook a meal, we would not expect the actor to stop after cutting just a single carrot. We would expect more to happen for us to be able to construct a situation model of a person cooking a meal. However, often the actor's goal is not clear. The goal is an internal feature and is therefore not always directly noticeable and obvious. Often, the goal has to be inferred from other aspects of an event, such as actors' movements and changes in location or in time (Radvansky \& Zacks, 2014).

Another factor that might affect the conceptualization of an event boundary is the speech context, e.g., the communicative status of the listener. Event conceptualization does not always happen in isolation. Most of the time, we are talking to one another about an event and sometimes we are describing an event with a certain listener or reader in mind. Papafragou and Grigoroglou (2019) argued that the person to whom we are talking affects how we conceptualize an event endpoint during message planning. Speakers might even define the endpoint of a simple event, for instance making a bed, differently depending on to whom they are talking: their mother or an exacting 5-star hotel manager. When talking to their mother, they are less worried about the end-state of a bed being made than when talking to a 5 -star hotel manager, who is expected to have a high standard on how a bed should be made.

In addition to grammatical aspect, there is another linguistic cue that also contributes to event endpoint conceptualization, that is, directional prepositions. We mentioned that many studies have experimentally studied the function of grammatical aspect in event comprehension. Directional prepositions, however, are currently under-studied in experimental research. The current study aims to experimentally investigate the effect of directional prepositions on event endpoint conceptualization when grammatical aspect is not involved. Therefore, we present more details on the linguistic definition of directional prepositions, in comparison to that of grammatical aspect, in the next section, to distinguish between grammatical aspect and directional prepositions concerning their role in event endpoint conceptualization. 


\section{Grammatical aspect and directional prepositions}

There is an abundance of complex linguistic literature on the distinction between grammatical aspect and lexical aspect (Comrie, 1976; Croft, 2012; Dowty, 1979; Langacker, 1987; Vendler, 1967). Grammatical aspect is known in the literature as being a grammatical way of representing the internal temporal structure of an event (e.g., ongoing or completed; Declerck, 2007). It is also called 'viewpoint aspect'. Imperfective aspect provides a viewpoint on the ongoing phase of an event and enables us to view the internal temporal contour of an event (e.g., he is writing a letter). Perfective aspect, however, emphasizes the completion of an event and offers an external viewpoint to inspect the event as a whole (e.g., he wrote a letter; Comrie, 1976; Langacker, 1987).

Unlike grammatical aspect, directional prepositions (such as to and towards) contribute to lexical aspect. As part of a verb phrase (e.g., walking to/towards the church), they refer to the inherent structure of an event (the telicity of an event): whether an event has an inherent endpoint or not. A distinction is often made in the literature between telic directional prepositions and atelic directional prepositions (for example, Krifka, 1998).

A telic directional preposition (e.g., to) is often labelled as a goal preposition (Bogaert, 2008; Eschenbach, Tschander, Habel, \& Kulik, 2000). When a telic directional preposition is used in a motion event description (e.g., he is walking to the house), the reference object (e.g., the house) is implied to be the goal of the agent. Therefore, this event is considered as having an inherent event endpoint and is thus a telic event. However, when an atelic directional preposition (e.g., towards) is used to describe a motion event (e.g., he is walking towards the house), there is no such implication. The reference object (e.g., the house) only implies the general moving direction of the agent. Therefore, the event is regarded as having no inherent event endpoint and is thus an atelic event.

In English, aspect is grammatically marked. The use of grammatical aspect in event descriptions is frequent and pervasive. The combinational use of grammatical aspect and directional prepositions (lexical aspect) is common, and they both contribute to the endpoint conceptualization. For example, he is walking to a church describes a telic event (church is implied by to as the inherent endpoint of the event of walking) that is still in progress and has not reached its inherent endpoint (an internal viewpoint provided by imperfective aspect). In other languages, grammatical aspect is not used or is rarely used. An example is Dutch (Flecken, 2011). As previously mentioned, the current study aims to understand the extent to which directional prepositions purely contribute to endpoint conceptualization when no effect comes from grammatical aspect. We chose Dutch in the current study for this reason (see detailed elaborations in the next section). 
Despite the fact that directional prepositions are experimentally understudied, they have been theoretically analyzed by many linguists (see Gruber, 1976; Piñón, 1993; Vandeloise, 2017; Verkuyl \& Zwarts, 1992; Zwarts, 2003, 2005, 2008; Zwarts \& Winter, 2000). Before introducing our experiments, we explain in the next section why Dutch is a suitable choice for our current study, considering its aspectual system. We also conduct some linguistic analyses on the two Dutch directional prepositions (i.e., naar and richting) based on the existing literature. In doing so, we present a clear picture of the semantic features of the two directional prepositions and provide a solid theoretical background for the hypotheses made in the current study.

\section{Theoretical background and the present study}

\subsection{TWO DUTCH DIRECTIONAL PREPOSITIONS: NAAR AND RICHTING}

Dutch is often considered as a non-aspectual language. It has progressive constructions, such as the aan-het construction and postural verb constructions (e.g., zitten te + infinitive), but they are less frequently used and hence more marked than the simple forms in Dutch (Flecken, 2011). They are often constrained by more contexts and more situation types than the simple forms (see event description studies in Flecken, 2011; Liao, Flecken, Dijkstra, \& Zwaan, 2020; von Stutterheim, Carroll, \& Klein, 2009). For instance, von Stutterheim et al. (2009) found that, when describing a motion event in which the agent moves in relation to a reference object, Dutch speakers exclusively used the simple present tense (e.g., Hij loopt naar/richting het station) instead of a progressive construction (e.g., Hij is naar/richting het station aan het lopen). This fact allows us to use the simple present tense in all our experiments that concern the same type of motion events, to eliminate the possible influence of grammatical aspect, and to focus purely on the role of directional prepositions with regard to endpoint conceptualization.

The two common directional prepositions in Dutch (i.e., naar and richting), therefore, became our topic of interest. Like to in English, naar in Dutch is also a goal preposition. It also implies the goal of the agent and hence a telic motion event that owns an inherent endpoint. It sounds odd to say hij liep urenlang naar de kerk 'he walked to the church for hours', but hij liep in twee uur naar de kerk 'he walked to the church in two hours' sounds perfectly fine.

Richting (meaning direction), on the other hand, is an atelic directional preposition in Dutch, which is similar to towards in English. It does not imply that the reference object is the goal of the agent and thus does not refer to an inherent endpoint of an event. Hij liep urenlang richting de kerk 'he walked towards the church for hours' sounds acceptable, but hij liep in twee uur richting 
de kerk 'he walked towards the church in two hours' sounds odd. Richting is originally a noun and is typically used in the phrasal preposition in de richting van 'in the direction of'. In fairly recent usage (in 1984; van der Sijs, 2001), it has been denominalized into a monomorphemic directional preposition that can be used independently in a sentence (Bakker \& Siewierska, 2002; Broekhuis, 2013; Norde, 2008).

As previously mentioned, directional prepositions have been investigated by many linguists. One common analysis in the linguistic literature is the traditional partitive analysis. According to the traditional partitive analysis, atelic directional PPs (e.g., richting-PPs, towards-PPs) denote parts of the complete paths denoted by telic directional PPs (e.g., naar-PPs, to-PPs). Similarly, this analysis is also applied to define imperfective aspect, such that imperfective telic sentences denote parts of complete VP-events (see Jackendoff, 1991; Krifka, 1998; Piñón, 1993; Verkuyl \& Zwarts, 1992).

Zwarts (2005), however, argued that the traditional partitive analysis works well with straight paths but not with curved paths. He took a new perspective and proposed that atelic directional PPs are comparatives, whereas telic directional PPs are superlatives. That is, if atelic directional PPs refer to paths that get 'nearer' to the reference object, then telic directional PPs refer to paths that get 'nearest' to the reference object (p. 766). This proposal captures the cumulative feature of atelic directional PPs (i.e., nearer and nearer to the reference object) and the non-cumulative feature of telic directional PPs (i.e., 'nearest' means that one cannot get any nearer to the reference object) (see Zwarts, 2005, 2008, for a detailed explanation of cumulativity). However, it fails to distinguish between, for example, to and towards in the sense that the former implies that the reference object is the goal of the agent, whereas the latter does not have this implication.

It is mentioned in Zwarts (2005) that, to is an "informationally stronger" preposition than towards (p. 765). This idea captures the main semantic characterization of the two types of prepositions, but it is not further elaborated nor studied in $Z$ warts. In the current study, we elaborate upon this idea by incorporating the existing literature on implicature studies (e.g., Buccola \& Haida, 2019; Grice, 1975; Zhan, 2018), and we apply it to distinguish between naar and richting. Two types of implicature are of relevance: scalar implicature and ignorance inference.

A typical example of scalar implicature comes from the use of quantifiers such as 'some' and 'all': the use of 'some' (e.g., Some students participated in this exam) leads to a scalar implicature that a stronger meaning 'all' is not satisfied (that is, not all students participated in this exam). An ignorance inference occurs when the speaker is ignorant about contextually based propositions. For example, when a speaker says she lives in Rotterdam or Amsterdam. The implicature is that the speaker is ignorant about both the proposition 'she lives 


\section{A STUDY OF NAAR AND RICHTING IN DUTCH}

in Rotterdam' and the proposition 'she lives in Amsterdam'. An ignorance inference also occurs when the speaker is uncertain about something stronger than what is said.

As previously mentioned, naar is a goal preposition and it implicates that the reference object is the goal of the agent, whereas richting does not have such implication. Based on this definition, we further propose that naar is a semantically stronger expression than richting. This is because the interpreter could adopt the above-mentioned Gricean reasoning and draw either of the following two inferences from the use of richting:

a. a scalar implicature: the speaker knows that naar is not satisfied; therefore, the speaker believes that the reference object is not the goal of the agent;

b. an ignorance inference: the speaker does not know whether naar is satisfied; therefore, the speaker does not know whether the reference object is the goal of the agent.

Following the above line of thought, we conducted a language comprehension task in Experiment 1. We asked participants to read sentences and drag a slider on a bar to indicate the distance between a moving agent and a reference object mentioned in these sentences. We hypothesized that when richting is used in a motion event description (e.g., hij loopt richting een kerk 'he walks towards a church'), participants would locate the agent further from the reference object than when naar is used (e.g., hij loopt naar een kerk 'he walks to a church'). This is because participants could conclude from inference (a) or inference (b) triggered by a richting-PP that the agent has or may have another goal instead of the reference object. Accordingly, they would locate the agent further from the reference object to leave room for the possibility that the agent deviates from the path to the reference object.

We furthermore investigated possible factors that might influence the choice between the two prepositions in event description tasks (Experiment 2 and Experiment 3). We have mentioned in the 'Introduction' two factors that might affect event endpoint conceptualization: the actor's goal and the interlocutor's status. We hypothesized that when the inferred goal of the actor is clearly the reference object, speakers should use naar more often than when it is not; This is also consistent with the idea in Experiment 1. Moreover, speakers should use naar more often when the speech context does not require cautious and accurate statements than when it does. The use of richting should exhibit the opposite patterns from the use of naar under the influence of these two factors. It is important to note that the simple present tense was used in the sentence stimuli of all three experiments. Reasons for this have been elaborated above (Flecken, 2011; von Sttuterheim et al., 2009). 


\subsection{PRE-REGISTRATION}

Hypotheses, sample size, materials, design, exclusion criteria, and analyses of all experiments reported in this paper were pre-registered on the Open Science Framework in advance of data collection and analysis. (See details at $<$ https:// osf.io/9ncdv/?view_only=b4751c303fbb4cd68a130f02b0d758cf >; <https:// osf.io/k52tx/?view_only=bddc5fe4c23b499e800795a816ab340d>; <https:// osf.io/7f2be/?view_only=4283aa91b93b4618891b4be6efac8440>. ${ }^{1}$ )

\subsection{FRICK'S COAST METHOD}

We adopted Frick's COAST method (Frick, 1998) to conduct flexible sequential testing during data collection for all three experiments in the current study. We adopted the sequential stopping rule that was proposed by Frick:

The researcher can perform a statistical test at any time. If the outcome of this statistical test is $p<.01$, the researcher stops testing participants and rejects the null hypothesis; if $p>.36$, the researcher stops testing participants and does not reject the null hypothesis; and if .01<p<.36, more participants are tested. (Frick, 1998, p. 691)

Frick conducted computer simulations to show that the conventional alpha level of .05 is preserved in this procedure.

There are two main reasons to adopt sequential analysis for our study. First of all, there were no similar experiments that had been done before. We could not infer an estimated effect size from an already existing and highly related study to perform an a priori power analysis. Second, as we mentioned in our pre-registration of Experiment 1, we did a pilot study for Experiment 1, but the effect size inferred from this pilot study was not reliable. This was because we used a small sample size in the pilot study. The power of the pilot study was not high enough to provide a reliable effect size to perform an a priori power analysis for the current study. A sequential analysis allowed us to test participants without having to determine a fixed sample size in advance of data collection. Therefore, we decided that sequential analysis was the best method to follow for all our experiments.

\section{Experiment 1}

Experiment 1 asked participants to read sentences and drag a slider on a bar to indicate the distance between a moving agent and a reference object mentioned in these sentences.

[1] Experiment 2 mentioned in this pre-registration is not included in the current study. 


\section{A STUDY OF NAAR AND RICHTING IN DUTCH}

We had three conditions in Experiment 1: richting, naar, and goal-reached conditions. To make sure that participants understood the task, we added the goal-reached condition as a control condition (using sentences like de man loopt de kerk in 'the man walks into the church'). If participants understood our task correctly, they should always drag the slider to the very right side of the bar to represent that the agent had arrived at the reference object when they read a goal-reached sentence. We hypothesized that the distance between an agent and a reference object would be the shortest in the goal-reached condition, compared to the naar and richting conditions.

Furthermore, we hypothesized that, when naar is used in the description of a motion event, participants would drag the slider, representing a moving agent, closer to a reference object than when richting is used; when richting is adopted, the location of an agent on the trajectory is less constrained by a reference object, given that the use of richting implies that the agent has or may have another goal instead of the reference object (i.e., participants would drag the slider further from a reference object to leave room for the possibility that the agent deviates from the path to the reference object).

\subsection{METHOD}

\subsubsection{Participants}

Participants were recruited from the Department of Psychology, Education, and Child Studies at Erasmus University Rotterdam. They all received course credits for their participation.

We adopted Frick's COAST method (Frick, 1998) to conduct flexible sequential testing during data collection while preserving an overall alpha level of .05. We decided to recruit participants in batches of 40 (as 40 was the minimum number of participants we decided to test). We would conduct a paired-samples $t$-test between the naar and richting conditions. According to the stopping rule proposed in Frick (1998), if the planned paired-samples $t$-test between the naar and richting conditions showed $p>.36$ or $p<.01$ after 40 participants (after data exclusion), we would stop testing participants. If $p$ was within these boundaries, we would test another 40 , determine $p$, and then decide if we needed another 40 . We would stop at $N=120$, regardless of the $p$-value of the paired-samples $t$-test at that time. Following this line of thought, we stopped data collection when the number of participants reached 56 (7 males, mean age 20.36, range: 18-28 years). This warranted that we had 40 participants after data exclusion for the first batch. This was also our last batch, given that the lower boundary of .01 was reached at this point. 


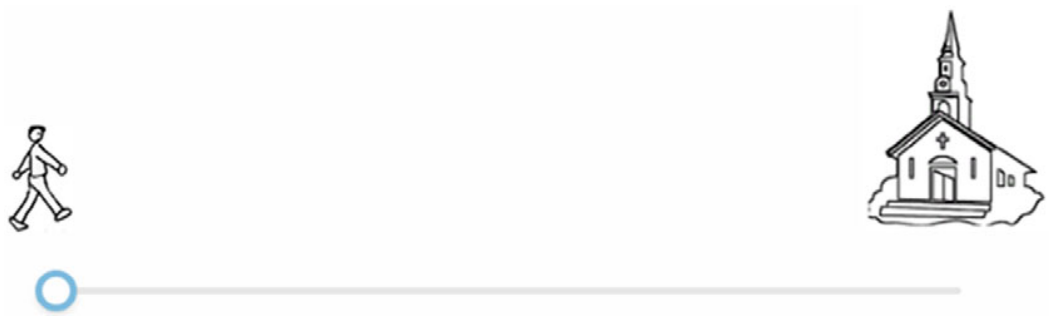

Fig. 1. An example of the pictures used in Experiment 1.

\subsubsection{Materials}

Experiment 1 was programmed using the Qualtrics Survey Software and used a slider answer option to represent a path (trajectory) between a moving agent (e.g., a vehicle, a person) and a reference object (e.g., a gas station, a church).

The moving agent was always presented on the left side of the bar with a value of 0 , whereas the reference object was presented on the right side with a value of 100 (see an example of the stimuli in Figure 1). Participants were asked to move the slider on the bar to a specific point to indicate the location of the moving entity based on the sentence they read (e.g., het meisje loopt naar de speeltuin 'the girl walks to the playground'). Values were not shown on the bar to prevent participants from making their decisions by remembering the displayed values instead of by reading the sentences carefully. Sixteen pictures with 8 different moving entities (man, woman, girl, boy, car, truck, van, and bus) and 16 different reference locations were created. Each moving entity was used twice in combination with the 16 locations to form the 16 pictures. Three sentences representing each condition were created for each picture. Thus, 48 sentences were formed (see 'Appendix I'). ${ }^{2}$

\subsubsection{Design and procedure}

Experiment 1 was a within-participants design in which 2 blocks (each with 24 sentences) were created. Each block contained 3 sentence types (richting, naar, and goal-reached sentences). The same reference object did not combine with the same directional preposition (i.e., richting or naar) in the same block. Thus, if a reference object was combined with a richting sentence in Block 1 , then it was combined with a naar sentence in Block 2 (for example, when the sentence de man loopt naar de kerk 'the man walks to the church' appeared in

[2] No filler items were added, given that it did not matter whether participants were making a conscious comparison between the conditions or not. It was even preferable if they knew they were comparing different prepositions because their responses were then more consistent. 


\section{A STUDY OF NAAR AND RICHTING IN DUTCH}

Block 1, then the sentence de man loopt richting de kerk 'the man walks towards the church' would only appear in Block 2). The order of blocks was randomized and the sentences within each block were also randomly presented.

Participants signed their name on an informed consent form first. They then filled out a questionnaire about their demographic information (i.e., age, gender, education) and linguistic background (i.e., native language). After that, participants were instructed to read a sentence and look at a scenario presented below the sentence. They were informed that the picture on the left side of the bar represented the moving person/vehicle they read in the sentence, the picture on the right side of the bar represented the location mentioned in the sentence, and their task was to drag the slider to indicate where the person/ vehicle was in relation to the location picture shown in the scenario on the basis of the sentence. They were told to imagine that the slider represented the moving entity when doing so. They did three practice trials first and then moved on to the experimental trials. This experiment took around 10 minutes. The language used in this experiment was Dutch.

\subsubsection{Exclusion criteria}

Participants who indicated that their first language was not Dutch and those who mentioned several languages as their mother tongue were excluded (12 out of 56 participants). This was to ensure that all participants were monolingual native Dutch speakers. We also removed Participant*Condition groups fulfilling at least one of the three criteria: (a) the standard deviation of the value on the slider was $>25$ (i.e., more than a fourth of the total range); (b) the standard deviation was $<1$ and the mean was $>95$ (i.e., where the slider value was just maxed out); and (c) the mean was $<5$ (i.e., essentially no directionality in sentences that were clearly directional). Based on these three criteria, we excluded a further 3 participants. In order to strictly follow our pre-registered sample size, we excluded the last participant to ensure we had exactly 40 participants for the first batch (which later on proved to be the only batch of participants we needed). Therefore, we excluded in total 16 out of the 56 participants we recruited.

\subsection{RESULTS AND DISCUSSION}

A paired-samples $t$-test was conducted in R (R Core Team, 2016) between the naar and the richting conditions. Results showed that participants dragged the slider significantly closer to the reference object in the naar condition $(M=$ $57.8, S D=20.6)$ than in the richting condition $(M=49.6, S D=21.6 ; t(39)=$ 3.604, $p<.001, d=0.39$ ). To also include the control condition, we built a multilevel linear model in $\mathrm{R}$ using the function lme in package $n l m e$ (Pinheiro, 


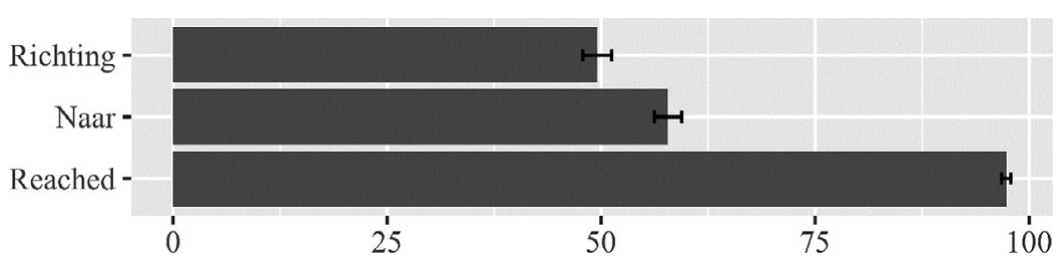

Fig. 2. Mean values of the position of a moving agent in relation to a reference object on the bar (from 0 to 100).

Bates, DebRoy, Sarkar, \& R Core Team, 2019). We adopted the model (Value $\sim$ Condition, random $=\sim 1 \mid$ Participant/Condition), given that Experiment 1 was a one-way repeated measures design and this model considered dependency in our data. The random effect we included in this model (random $=\sim 1$ | Participant/Condition) specified that the data of different levels of Condition were from the same participant. Besides that, we included in this model our predictor Condition. To assess the overall effect of Condition, we built a baseline model that did not include the predictor Condition but did include the intercept and the random effect (Value $\sim 1$, random $=\sim 1 \mid$ Participant/ Condition). A model comparison using the ANOVA function showed that our predictor Condition had a significant effect on the values shown on the $\operatorname{bar}\left(\chi^{2}(2)=147.8803, p<.001\right)$. Additional Tukey post-hoc analyses using the function glht from the package multcomp in R (Hothorn, Bretz, \& Westfall, 2008) also showed that there was a significant difference between the naar condition and the richting condition $(\beta=8.178, S E=2.640, z=3.098, p=.006)$. Moreover, there was a significant difference between the goal-reached condition and the naar condition $(\beta=39.600, S E=2.640, z=15.001, p<.001)$, and between the goal-reached condition and the richting condition $(\beta=-47.778, S E=2.640, \mathrm{z}$ $=-18.009, p<.001)$. Figure 2 presents the mean values of the position of a moving agent in relation to a reference object (a potential destination) on the bar (the larger the value, the closer an agent is to a reference object).

Our findings support our hypothesis. Participants indeed located the agent significantly further from the reference object when richting was used than when naar was used. By doing so, they assumed the possibility that when richting is used the moving agent has another goal instead of the reference object, and deviates from the path to the reference object. In other words, they were more certain about the reference object being the goal of the agent when naar was used than when richting was used.

This leads to the following question. What are the factors that affect a speaker's certainty about the reference object being the goal of the agent, and subsequently the choice between naar and richting? We used event description tasks to answer this question in Experiment 2. We investigated two factors (i.e., the actor's goal and the interlocutor's status) in Experiment 2. Experiment 3 was an extension of 
Experiment 2. We manipulated the strength of the actor's goal in Experiment 3 and tested whether a stronger intention/goal had a larger effect.

\section{Experiment 2}

We aimed to investigate two possible factors that might influence the use of naar and richting in real-life situations: the actor's goal (Intention) and the interlocutor's status (Context). We hypothesized that naar should be used more often when the actor's goal could be inferred from the referential situation. For example, a man is walking with a trash bag in his hand and there is a trash bin in the near distance. The trash bin could be used as an inference that the man's goal is to throw the trash bag into the trash bin. On the other hand, richting should be chosen more frequently when the reference object could not be inferred as the goal of the agent in the referential situation. For example, a man is walking with nothing in his hand and there is a trash bin in the near distance. There is no extra information in the referential situation that can be used to infer that the trash bin is the goal of the man.

We furthermore hypothesized that speech context should also affect the choice between the two prepositions. For example, when there is a (perceived) requirement of an accurate description of an event, such as talking to a police officer, people should be more conservative and cautious with their linguistic choice than normally (Ainsworth, 1993). This means that they should use richting more often than they normally do, for richting does not come with the implication that the reference object is the goal of the agent.

Specifically, Experiment 2 tested the choice between naar and richting in two different referential situations (an intention shown vs. no intention shown) and in two distinct contexts (a description to a police officer vs. to a friend). To manipulate intention, we created two versions of a picture. In both versions, a person was shown and the same reference object was placed in its near distance. The person was either holding something that was semantically related to the reference object (e.g., a trash bag vs. a trash bin) or not holding anything. In total we created two different pictures, each with two versions (see 'Appendix II').

To manipulate context, we created two versions of the instructions for each version of each picture. The instruction was either "You describe the following scenario to a police officer as a witness. Please choose a word that you think fits better in the sentence" (e.g., hij loopt (?) de container) or "You describe the following scenario to a friend. Please choose a word that you think fits better in the sentence" (literally translated from the original Dutch versions). Naar and richting were the options shown below each scenario.

We hypothesized that (1) naar should be chosen more often when there is an intention of arriving at the reference object than when there is no such 
intention shown in the referential situation; richting should exhibit the opposite pattern; and (2) richting should be adopted more often when participants are required to describe a scenario to a police officer than to a friend; naar should show an opposite pattern. Overall, we hypothesized a main effect of Intention and a main effect of Context on the choice between richting and naar.

\subsection{METH O D}

\subsubsection{Participants}

As in Experiment 1, we adopted Frick's COAST method to conduct flexible sequential testing. We decided to recruit participants in batches of 160 (the minimum number of participants we planned to test), 10 in each cell (that is, 80 per intention and 80 per context). If $p<.01$ or $p>.36$ for each main effect we tested (Intention and Context), we would stop testing participants. If $p$ was within these boundaries for any one of the two main effects predicted, we would test another 160 participants. We would stop at $N=480$ (240 per intention and 240 per context), regardless of the $p$-values at that time. In the end, we collected valid data from 480 participants (203 males, mean age 22.34, range: 16-71 years) after excluding 17 participants whose mother tongue was not Dutch. Participants were recruited in various ways, such as by posting the survey link on social media, sending e-mails, or asking people on campus, etc.

\subsubsection{Materials}

Experiment 2 was programmed using the Qualtrics Survey Software. Two scenarios were created and each scenario was created with two versions (with intention and without intention (see 'Appendix II'): a person dragging a trash bag with a posture of walking and a trash bin in the near distance (with intention) / the same person without dragging a trash bag with a posture of walking and the trash bin in the near distance (without intention); a person holding a bike with a posture of walking and a bike repair shop in the near distance (with intention) / the same person without holding a bike with a posture of walking and the bike repair shop in the near distance (without intention).

The person with/without an object in their hand was always on the left side of the display and the referred object was always on the right. A sentence was shown below each scenario, for example, hij loopt (?) de container 'he walks (?) the trash bin'. A choice between naar and richting was shown below the sentence (see an example of the stimuli in Figure 3). 


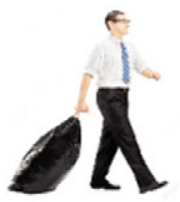

Hij loopt ( ? ) de container.

naar

richting

Fig. 3. An example of the stimuli used in Experiment 2 (with an intention shown in the referential scenario).

\subsubsection{Design and procedure}

Sixteen cells were created $(2$ Scenario $\times 2$ Intention $\times 2$ Context $\times 2$ Option Order). Instructions were manipulated between 'a description to a police officer' and 'a description to a friend' (Context). The order of naar and richting as options was counterbalanced (Option Order). This experiment was a between-participants design. Each cell presented only one item. Each participant was randomly assigned to any one of the 16 cells. Participants first read an informed consent form attached to the survey. After they agreed to continue with the survey, they then answered online questions about their demographic information (i.e., age, gender) and linguistic background (i.e., native language). After that, they read the instruction that appeared on the screen, made a choice between naar and richting based on the scenario they saw by completing the incomplete sentence shown below the scenario (e.g., hij loopt (?) de container 'he walks (?) the trash bin').

\subsection{RESULTS AND DISCUSSION}

\subsubsection{Confirmatory analyses}

A binomial logistic regression model that included the main effect of Intention and the main effect of Context was conducted in $\mathrm{R}$ using the $\mathrm{glm}$ function implemented in the package lme4 (Bates, Mächler, Bolker, \& Walker, 2015). ${ }^{3}$

[3] In the pre-registration, we stated that we would include the random effect of items in our binomial logistic regression model (the formula used in R: preposition $\sim$ intention + context $+(1 \mid$ item $)$ ). However, we obtained a singular fit using this model. This often indicates that the model is overfitted. Moreover, the AIC value of a more parsimonious model (with only the fixed effects of Intention and Context) was lower than that of the model that included the random effect of items (202.5 vs. 204.6). This means that the parsimonious model is better. Therefore, we decided to adopt a binomial logistic regression model that only contained the two fixed effects (i.e., Intention and Context; the formula used in R: preposition intention + context). This model was used for the analysis of the later added data as well (i.e., the second and the third batch of data). 


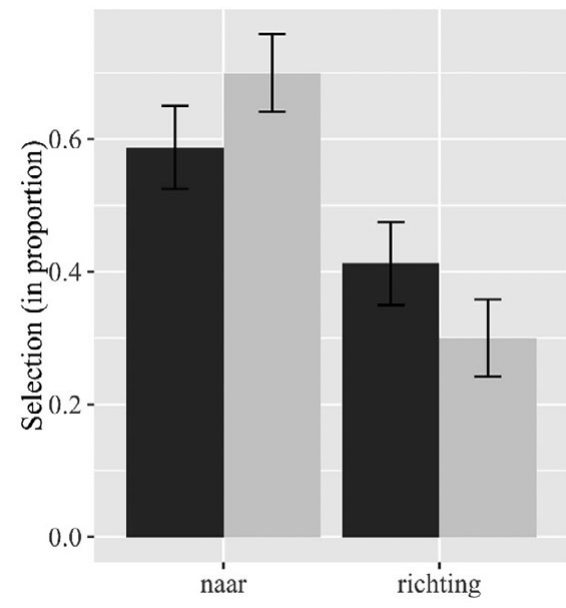

Intention no yes

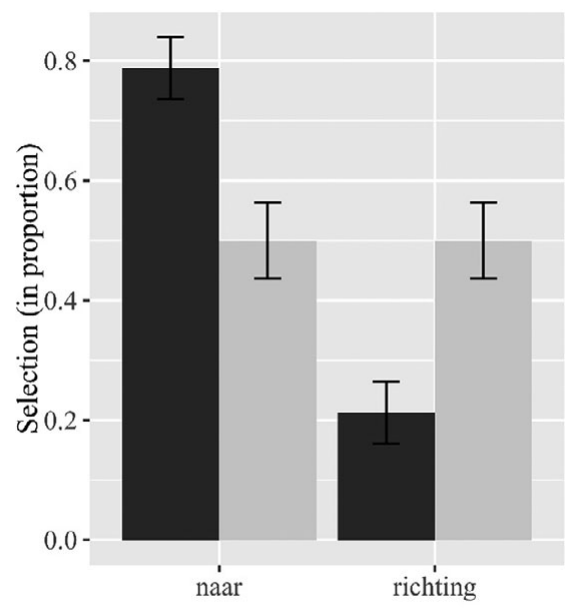

Interlocutor $\square$ friend police

Fig. 4. Mean proportions of the selection of the two prepositions (i.e., naar and richting) in each Intention condition (left) and in each Interlocutor condition (right).

Both factors were dummy coded. In the first batch of collected data $(N=160)$, we did not find a significant main effect of Intention but the $p$-value was within the boundary from .01 to $.36(\beta=-0.35, S E=0.34, z=-1.024, p=.31$, odds ratio: $0.70,95 \%$ CI: $0.35-1.38$ ). We did find a significant main effect of Context ( $\beta=1.515, S E=0.35, z=4.374, p<.001$, odds ratio: $4.55,95 \%$ CI: $2.34-9.13$ ). Given that the $p$-value found for the effect of Intention was within the boundary from .01 and .36 , we continued data collection until we reached 480 participants. The $p$-value of the main effect of Intention reached lower than .01 when $N=480(\beta=-0.544, S E=0.20, z=-2.686, p=.007$, odds ratio: $0.58,95 \%$ CI: $0.39-0.86$ ): based on the standards of the sequential analysis we pre-registered, it was considered as a significant effect. A significant main effect of Context remained when $N=480(\beta=1.331, S E=0.21, z=6.462, p<.001$, odds ratio: $3.79,95 \% \mathrm{CI}: 2.54-5.70$ ). Figure 4 shows the mean proportions of the selection of each preposition in each Intention condition and in each Interlocutor condition (i.e., Context).

\subsubsection{Exploratory analyses}

Besides the main effects of Intention and Context on the choice between naar and richting, we were interested in whether the scenario type (a trash bin in the near distance or a bike shop in the near distance) showed a main effect or an interaction effect with Intention or with Context. Moreover, we were also 
interested in whether there was a main effect of Option Order (i.e., naar/ richting or riching/naar). Therefore, we built a binomial logistic regression model that included the main effect of Intention, Context, Option Order, Scenario, the interaction between Scenario and Intention, and the interaction between Scenario and Context (the formula used in R: preposition $\sim$ intention*scenario + context*scenario + option order $)$. All the factors were sum coded except for the factor Option Order (dummy coded), as we were interested in only the main effect of this factor. Significant main effects of Intention (intercept $\beta=-1.024, S E=0.15, z=-6.657, p<.001 ; \beta=0.278, S E=0.10, z=$ $2.708, p=.007$, odds ratio: $1.32,95 \% \mathrm{CI}: 1.08-1.62)$ and Context $(\beta=-0.685, S E$ $=0.11, z=-6.526, p<.001$, odds ratio: $0.50,95 \% \mathrm{CI}: 0.41-0.62)$ were remained in this model. There was no significant main effect of Scenario $(\beta=0.096, S E=$ $0.10, z=0.919, p=.36$, odds ratio: $1.10,95 \% \mathrm{CI}: 0.88-1.35)$. No interaction effect was found between Scenario and Intention $(\beta=0.045, S E=0.10, z=$ $0.434, p=.67$, odds ratio: $1.05,95 \%$ CI: $0.86-1.28)$, nor between Scenario and Context $(\beta=0.026, S E=0.11, z=0.249, p=.80$, odds ratio: $1.03,95 \% \mathrm{CI}: 0.84$ 1.26). There was a significant main effect of Option Order $(\beta=0.680, S E=0.21, z=3.305, p<.001$, odds ratio: $1.97,95 \% \mathrm{CI}: 1.33-2.97)$. Participants used richting more often when the option order was shown as richting/ naar than when it was naar/richting.

In sum, our findings support our hypotheses on the main effect of Context and the main effect of Intention. We found a significant effect of Context on the use of naar and richting. That is, when participants were required to describe a scenario to a police officer, they were more cautious and more conservative with their linguistic choice, and they used richting 3.79 times more often than when they were asked to describe the scenario to a friend. As expected, the opposite pattern occurred for the use of naar. Naar was used 3.79 times more often in the context of talking to a friend than in the context of talking to a police officer. We take this to mean that, when the speech context was talking to a friend, participants were less careful in making a certain statement and resorted to the default. Given that naar is very common in daily conversations, participants showed a more frequent use of naar in the context of talking to a friend than that of talking to a police officer. We also found a significant effect of Intention on the use of naar and richting. Specifically, when there was an intention shown going to a certain place (e.g., a trash bag and trash bin, a broken bike and a bike repair shop), participants used naar 1.72 times (1/0.58) more often than when no intention of going to a certain place was presented. The opposite pattern appeared for the use of richting. However, this effect is smaller than the effect of Context (odds ratios: 3.79 vs. 1.72).

Why is the effect of Intention on the use of naar and richting smaller than that of Context? Perhaps our manipulation of intention was not powerful enough. We used one picture with a person dragging a trash bag with a trash bin in the 
near distance, and another picture with a person holding a bike and a bike shop in the near distance. Both pictures only showed a relational combination of two objects that belong to the same semantic category (e.g., trash bag and trash bin; bike and bike shop). Their relation might not be strong enough to imply that a trash bag would necessarily be thrown into a trash bin and a bike would definitely be taken to a bike shop. When the conversational context implies a more conservative and cautious answer, the uncertainty that one object (e.g., the trash bag) does not necessarily end at the other (e.g., the trash bin) becomes even stronger. Therefore, we hypothesized that the effect of Intention would get stronger if we could increase the strength of intention, which is what we tried to accomplish in Experiment 3.

\section{Experiment 3}

Following the above line of thought, Experiment 3 investigated the effect of Intention on the use of naar and richting by increasing the strength of intention. We hypothesized that, when an intention could be more readily inferred from the picture, speakers should use naar more often than when the intention is not as salient. We manipulated the degrees of intention from strong, via moderate to weak. Compared to Experiment 2, the addition was the strong condition (see details in the 'Materials' section). Furthermore, we only retained the context of talking to a police officer from that experiment. As Experiment 2 showed, speakers used richting as often as naar (naar vs. richting: 120 vs. 120) when the speech context was a description to a police officer, whereas naar was dominantly used (naar vs. richting: 189 vs. 51) when it directed at a friend. This suggests that there is more room to detect an increase of the use of naar when the context is talking to a police officer instead of to a friend. There might be a ceiling effect on the use naar when the interlocutor is a friend. Therefore, our hypothesis was that in the context of talking to a police officer, with the increase of the strength of intention of motion from weak, moderate, to strong, the use of naar would, accordingly, increase.

\subsection{ME T H O D}

\subsubsection{Participants}

As in Experiment 2, we adopted Frick's COAST method to conduct flexible sequential testing. We decided to recruit participants in batches of 120 (the minimum number of participants we planned to test), 20 in each cell (that is, 40 per scenario: strong vs. moderate vs. weak). If $p>.36$ or $p<.01$ for the main effect of Scenario and each comparison we tested, we would stop testing participants. If $p$ was within these boundaries for the main effect of Scenario 


\section{A STUDY OF NAAR AND RICHTING IN DUTCH}

and any one of the three comparisons, we would test another $120(N=320$; 160 per intention and 160 per context). We stopped when the number of participants reached 540 (251 males, mean age 21.34 , range: $17-38$ years $)^{4}$ after excluding 13 participants whose mother tongue was not Dutch. Participants were recruited mainly by asking people on campus.

\subsubsection{Materials}

This experiment was programmed using the Qualtrics Survey Software. Three scenarios were created. The strong condition showed a fire truck with its siren on and a building on fire in the near distance. In this condition, there is a causal connection between the fire truck and the building that is on fire. That is, there is a big fire nearby, the fire truck has its siren on and is therefore on its way to combat the fire.

The moderate condition showed a fire truck with its siren off and a fire station in the near distance. In this condition, there is a semantic connection between the fire truck and the building but not necessarily a causal one. A fire truck with its siren off is not necessarily going to a fire station. It can be that it is still going to a building that is on fire (since the road is not busy, the siren can be off) or going to another fire station.

Finally, the weak condition showed a fire truck with its siren off and a church in the near distance. In this case, there is no particular connection between the fire truck and the building. They do not even belong to the same semantic category. When people talk about a fire truck, they normally do not think of a church (see all the stimuli in 'Appendix III').

A sentence was shown below each scenario, for example, de brandweerauto rijdt (?) het brandende gebouw 'the fire truck drives (?) the building on fire'. Participants had to choose between naar and richting to complete the sentence based on the scenario they saw. Participants' age, gender, and mother tongue were also recorded.

\subsubsection{Design and procedure}

Six cells were created ( 3 Scenario $\times 2$ Option Order). The order of naar and richting as options was counterbalanced. As in Experiment 2, Experiment 3 was also a between-participants design. Each cell had only one item. Each participant was randomly assigned to any one of the 6 cells. Participants first read an informed consent form attached to the survey. After they agreed to

[4] In the pre-registration, we stated that we would stop data collection when the number of participants reached 360 . However, we decided to continue data collection because the $p$-value of the main effect of Scenario was still within the boundary of .01 to .36 when $N=360$. 
continue with the survey, they then filled in their demographic information (i.e., age, gender) and linguistic background (i.e., native language). After that, they followed the instruction that appeared on the screen (Please describe the scenario to a police officer as a witness), and made a choice between naar and richting, based on the scenario they saw, to complete the incomplete sentence shown below the scenario (e.g., de brandweerauto rijdt (?) het brandende gebouw 'the fire truck drives (?) the building on fire').

\subsection{NORMING STUDY}

To ensure that there was indeed a difference in the degree of connection between the two objects shown in the three scenarios, we performed a norming study. We asked 120 Dutch speakers (40 per scenario) to rate the possibility of the fire truck's destination being a building on fire / a fire station / a church using a 7-point Likert scale (very likely, moderately likely, a bit likely, neither likely nor unlikely, moderately unlikely, a bit unlikely, very unlikely: from 1 to 7). Each participant was assigned to only one of the three scenarios to avoid them forming conscious comparisons between scenarios and from overthinking (e.g., the same fire truck with three destinations). We found that $40 \%$ (16 out 40 ) and $30 \%$ (12 out of 40 ) participants chose 'very likely' and 'moderately likely', respectively, for the scenario with a strong intention (i.e., a fire truck with its siren on and a building on fire; possibility rating from 1 to 7 : $M=2.58,95 \% \mathrm{CI}=1.95-3.21) .12 .5 \%$ (5 out of 40$)$ and $32.5 \%$ (13 out of 40$)$ participants chose 'very likely' and 'moderately likely', respectively, for the scenario with a moderate intention (i.e., a fire truck with its siren off and a fire station; possibility rating from 1 to $7: M=3.15,95 \% \mathrm{CI}=2.65-3.66)$. Only $2.5 \%$ ( 1 out 40 ) and $7.5 \%$ (3 out 40 ) participants chose 'very likely' and 'moderately likely', respectively, for the scenario with a weak intention (i.e., a fire truck with its siren off and a church; possibility rating from 1 to $7: M=4.55,95 \% \mathrm{CI}=4.06-5.04)$. We assume that the extent to which speakers choose 'very likely', compared to other possibility options, actually determines whether they use naar or richting in their language production. Any bit of uncertainty in this respect might lead to the use of richting in real speech. Only when speakers are very certain about the destination (when they choose 'very likely') will they use naar in the context that requires speech accuracy (e.g., talking to a police officer). Therefore, we did find a difference between these three scenarios, in the sense that people chose 'very likely' much more often for the building on fire scenario than the other two scenarios (building on fire vs. fire station vs. church: $40 \%$ vs. $12.5 \%$ vs. $2.5 \%$ ). 


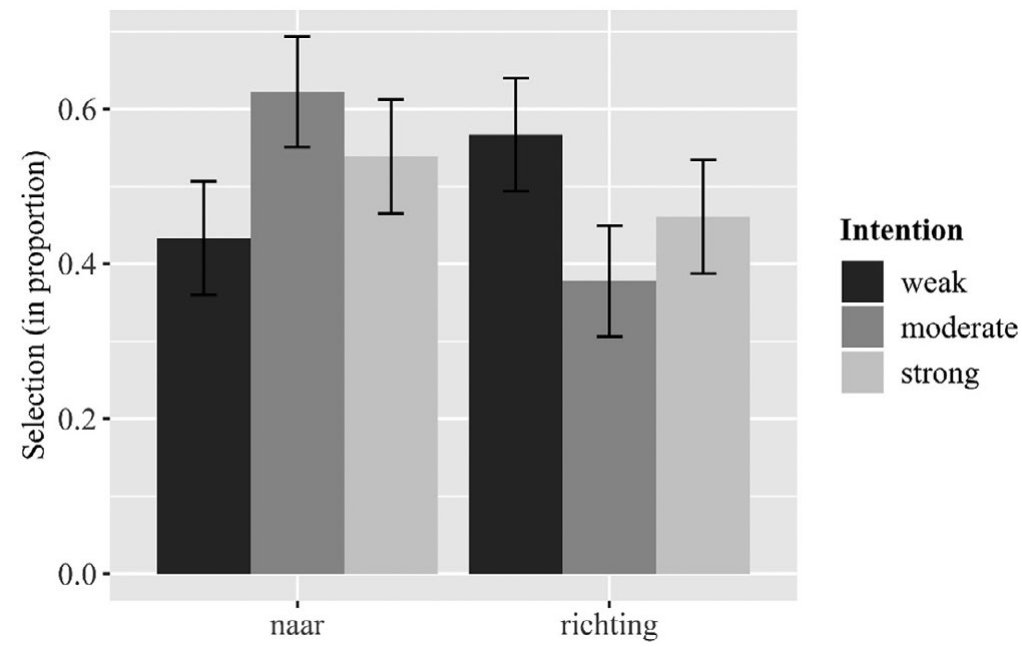

Fig. 5. Mean proportions of the selection of the two prepositions (i.e., naar and richting) in each Intention condition (i.e., weak, moderate, strong).

\subsection{RESULTS AND DISCUSSION}

A binomial logistic regression model that included the main effect of Scenario was conducted in $\mathrm{R}$. This factor was dummy coded. We found a significant difference between IntentionModerate and IntentionWeak (intercept $\beta=-$ $0.499, S E=0.1537, z=-3.246, p=.001 ; \beta=0.7673, S E=0.2151, z=$ $3.567, p<.001$, odds ratio: $2.15,95 \% \mathrm{CI}: 1.42-3.29)$. There was no significant difference between IntentionStrong and IntentionWeak $(\beta=0.4241, S E=$ $0.2121, z=2.000, p=.046$, odds ratio: $1.53,95 \% \mathrm{CI}: 1.009-2.320$ ), nor was there a significant difference between IntentionStrong and IntentionModerate $(\beta=0.3431, S E=0.2145, z=1.600, p=.110$, odds ratio: $1.41,95 \% \mathrm{CI}: 0.93-$ 2.15). An extra Wald test showed that there was a significant main effect of Scenario $\left(\chi^{2}(2)=12.8, p=.002\right)$. Figure 5 exhibits the mean proportions of the selection of each preposition in each Intention condition.

Experiment 3 supports what we found in Experiment 2; that is, naar was used significantly more often when there was an intention of arriving at the reference object than when there was no such intention (IntentionModerate vs. IntentionWeak: $p<.001)$. However, contrary to our prediction, we did not find an increased effect of Intention even though we increased the salience of the intention. Instead, the expected moderate degree of intention had, if anything, a stronger effect than the expected strong degree of intention (odds ratios: 1.53 vs. 2.15). Possible reasons will be discussed in the 'General discussion' section. 


\section{General discussion}

We conducted three experiments to examine event endpoint conceptualization. Two Dutch directional prepositions (i.e., naar and richting) provide a useful paradigm to ask precise questions about endpoint conceptualization. Experiment 1 adopted a sentence comprehension task and confirmed the linguistic proposal that the two directional prepositions differ in their implication on the goal of the agent. Experiment 2 and Experiment 3 used this linguistic pair to test the effect of two factors (i.e., the actor's goal and the interlocutor's status) on event endpoint conceptualization via language production tasks.

Experiment 1 used a slider dragging task and showed that when richting was used to describe a motion event, participants placed the moving agent further from the reference object than when naar was adopted; moreover, when a goalreached expression was used, participants placed the moving agent nearest to the reference object.

It is proposed that comprehenders adopted Gricean reasoning when deciding on the distance between the moving entity and the reference object. The three expressions (i.e., naar, richting, and goal-reached expressions) differ in their strength of semantics. Distances were divided up into three corresponding sections based on their semantics (i.e., scalar implicature): nearest/inside, near, and not near. A goal-reached expression means that the agent arrives at the reference object (that is, nearest to the reference object / inside the reference object). It is semantically the strongest, compared to naar and richting. Naar implies that the reference object is the goal of the agent but the goal is not yet reached. Therefore, on a semantic scale, it is not as strong as a goal-reached expression. Accordingly, the agent was placed not as close to the reference object as a goal-reached expression, but near it. Richting has the weakest semantics, given that it triggers the inferences that the agent has or may have another goal instead of the reference object. Therefore, participants located the agent the furthest from the reference object, compared to the other two expressions. By doing so, they left room for the possibility that the agent deviates from the path to the reference object and goes to other places.

Having shown that richting and naar indeed differ semantically, we set out to investigate factors that might affect the use of the two words and hence endpoint conceptualization in Experiment 2 and Experiment 3. In both experiments, we asked participants to make a very specific linguistic choice between naar and richting based on a motion scenario they were presented with. This task is simple and ecological. By giving participants a well-defined task, we obtained a linguistic report that can be taken as an indicator of the thought process that occurs during decision-making (Ericsson \& Simon, 1993).

In Experiment 2, as hypothesized, we found a very strong main effect of Interlocutor (odds ratio: 3.79). Specifically, when participants were required 
to describe a scenario of a person moving naar or richting, they used richting more often when they were asked to describe the scenario to a police officer than to a friend. This presumably occurred because they wanted to be more cautious and more conservative with their linguistic choice when the recipient of their description was an officer of the law. Whereas naar implies that the goal of the person is the reference object, richting merely indicates the direction. In other words, by using naar, participants were committing themselves to stating the goal of the protagonist, something they were less willing to do when talking to a police officer. When the context was talking to a friend, participants showed a more frequent use of naar, compared to that of talking to a police officer. This finding provides empirical support for the view that contextual factors affect endpoint conceptualization ((Papafragou \& Grigoroglou, 2019).

One might argue that the effect of Interlocutor might be due to the formality of the situation (i.e., register). Describing an event to a police officer normally requires a more formal register than to a friend. Richting, as a denominalized preposition, might appear more often in a more formal register than naar. Hence, richting was used more often when the interlocutor was a police officer instead of a friend. This line of argument is plausible but does not provide the main reason for the effect. The chief reason for a person to choose between naar and richting still has a semantic basis (i.e., a goal or a direction), a semantic basis that is also evident in the effect of the type of stimuli, which we will discuss next. Moreover, in formal occasions, people usually feel the need to be cautious with their statements. Talking to a police officer is very likely to be an example of this. Therefore, we propose that register is a possible factor that can affect the choice between naar and richting, but is definitely not the only or main reason, and it can go hand in hand with other reasons (i.e., being cautious, accurate, and specific).

In addition to the effect of the social status of the interlocutor, we found that the choice between naar and richting was also influenced by the characteristic of the stimulus, namely the degree to which the intention of the protagonist going to the reference object could be inferred from the stimulus. This also supports our hypothesis. Specifically, when it could be inferred that the reference object in the display was the goal of the agent, participants used naar more often than when no clear inference was presented (i.e., no trash bag or bike was shown), and the opposite patterns occurred for richting. This finding clearly confirms the idea that knowing the actor's goal of performing an action is important in event endpoint conceptualization. However, this effect was smaller than the effect of Interlocutor (odds ratios: 1.72 vs. 3.79).

In Experiment 3 we tried to increase the salience of the intention shown in the referential situation and investigated whether this would increase its effect on the use of naar and richting. We argued that there is a semantic relation between, for instance, a trash bag and a trash bin. That is, these two concepts 
belong to the same semantic category and they do co-occur in the same text frequently. ${ }^{5}$ We proposed that such a relation, however, might not be strong enough to exhibit a strong effect of Intention. The mere presence of a trash bin does not necessarily cause a trash bag to be thrown in it. Hence, we created a causal relation in Experiment 3 that we argued could be a stronger semantic relation (i.e., a fire truck and a burning building). However, we did not find a significant difference between the causal scenario and the relational scenario, not even between the causal scenario and the irrelevant scenario, in the use of naar and richting. Participants did not use less richting / more naar in the causal scenario than in both the relational scenario and the irrelevant scenario.

This unpredicted finding prompts further thoughts. One possible reason is that, although a burning building is indeed a more salient goal for the fire truck driver than a fire station when the siren of the fire truck is on, the inference that the fire truck driver's goal is the burning building shown in the referential situation is still a defeasible inference. That is, people can still think of other places being the fire truck driver's goal instead of the one shown in the referential situation; for example, another burning building. Therefore, it is not evident that we would find a stronger effect of Intention if we choose a burning building as the reference object rather than a fire station. Another possibility is that we ignored a possible 'ongoingness' implication in the strong condition. That the building is on fire implies that this situation is happening right now. This could create a sense of urgency, which makes participants want to emphasize that the firetruck is on its way and is getting nearer and nearer to the reference object. Richting then becomes a more proper choice than naar in this case, given that richting emphasizes the direction and the trajectory of motion.

As mentioned earlier, Zwarts $(2005,2008)$ proposed that atelic directional PPs have a cumulative nature, whereas telic directional PPs do not. Atelic directional PPs denote paths of a progression that are connected and add up cumulatively. This proposal might point out the progressive and dynamic nature of atelic directional PPs, such as richting-PPs, and indicate that the use of richting-PPs in event descriptions creates a richer mental representation with more details on what is happening along the way than the use of naar-PPs. This kind of use of richting is reminiscent of the role progressive aspect plays in event descriptions. There is empirical support for the claim that the use of progressive aspect makes the details on the happening of an event more available, for example, actions of the character, location, etc., than the use of perfective

[5] We searched collocations of the word 'trash' via Sketch Engine and found that there was a high association strength between the word 'trash' and the word 'bin', 'dumpster', and 'container': with a $\log$ Dice of $8.80,8.31,7.75$, respectively (for more explanations about logDice, see Rychlý, 2008, and Gablasova, Brezina, \& McEnery, 2017). 
aspect (Ferretti, Kutas, \& McRae, 2007; Matlock, 2011). For future research, it would therefore be meaningful to test experimentally whether the use of richting indeed evokes a more detailed representation of a depicted event, compared to the use of naar.

Future research should also explore more languages that differ in their aspectual systems. For instance, English differs from Dutch in its aspectual system, given that aspectual markers are more grammaticalized in English than in Dutch. It would then be useful to study whether to and towards in English work the same way as naar and richting work in Dutch, or whether the use of progressive aspect in English creates a different understanding and use of to and towards. It is possible that the function of towards in English is less salient than that of richting in Dutch in representing an event, as progressive aspect in English might direct the comprehender's attention to other aspects of the event, for instance, the actor's manner. By investigating more languages, we are able to build a systematic understanding of how grammatical aspect and directional prepositions interplay in building situation models of an event.

\section{Conclusion}

Our results contribute to a deeper understanding of event cognition and event conceptualization. Spatial relations between one entity and another entity offer important information in building an event model (Radvansky \& Zacks, 2014; Zwaan \& Radvansky, 1998). By employing experimentally less-studied linguistic features (i.e., two directional prepositions in Dutch: naar and richting), we are able to assess the extent to which the two directional prepositions differ in representing the spatial relations in an event through a sentence comprehension task. Our study shows that people are sensitive to such spatial relations, whether the reference object is the goal or just an indicator of the direction of a moving agent when building an event model.

Moreover, we used an event description task to explore the effect of two factors (i.e., the actor's goal and the interlocutor's status) on event conceptualization, targeting endpoint conceptualization. We find that both factors affect how people conceptualize an event endpoint. Our study manifests the importance of considering contextual factors, such as the social status of the interlocutor, in event description studies.

\section{REFERENCES}

Ainsworth, J. E. (1993). In a different Register: the pragmatics of powerlessness in police interrogation. Yale Law Fournal 103(2), 259-322.

Anderson, S. E., Matlock, T. \& Spivey, M. (2013). Grammatical aspect and temporal distance in motion descriptions. Frontiers in Psychology 4, 337, e2013.00337. 


\section{LIAO ET AL.}

Bakker, D. \& Siewierska, A. (2002). Adpositions, the lexicon and expression rules. In R. M. Usón \& M. J. Pérez Quintero (eds), New perspectives on argument structure in functional grammar (pp. 125-178). Berlin: Mouton de Gruyter. Online <https://eprints.lancs.ac.uk/id/ eprint $/ 1345 />$.

Bates, D., Mächler, M., Bolker, B. \& Walker, S. (2015). Fitting linear mixed-effects models using lme4. Fournal of Statistical Software 67(1), 1-48.

Becker, R. B., Ferretti, T. R. \& Madden-Lombardi, C. J. (2013). Grammatical aspect, lexical aspect, and event duration constrain the availability of events in narratives. Cognition 129(2), 212-220.

Bogaert, P. (2008). A qualitative calculus for moving point objects constrained by networks Unpublished doctoral dissertation, Ghent University. Online <http://hdl.handle.net/1854/ LU-469203>.

Broekhuis, H. (2013). Syntax of Dutch: adpositions and adpositional phrases. Amsterdam: Amsterdam University Press.

Buccola, B. \& Haida, A. (2019). Obligatory irrelevance and the computation of ignorance inferences. Fournal of Semantics 36(4), 583-616.

Comrie, B. (1976). Aspect: an introduction to the study of verbal aspect and related problems. Cambridge: Cambridge University Press.

Croft, W. (2012). Verbs aspect and causal structure. New York: Oxford University Press.

Declerck, R. (2007). Distinguishing between the aspectual categories "(a)telic", "(im)perfective " and "(non)bounded ". Kansas Working Papers in Linguistics 29, 48-64. doi:10.17161/ kwpl.1808.1787.

Dowty, D. R. (1979). Word meaning and Montague grammar: the semantics of verbs and times in generative semantics and in Montague's Ptq. Berlin: Springer Science \& Business Media.

Ericsson, K. A. \& Simon, H. A. (1993). Protocol analysis: verbal reports as data, rev. edn. Cambridge, MA: MIT Press.

Eschenbach, C., Tschander, L., Habel, C. \& Kulik, L. (2000). Lexical specifications of paths. In: C. Freksa, C. Habel, W. Brauer \& K. F. Wender (eds), Spatial cognition II: lecture notes in computer science (Vol. 1849, pp. 127-144). Berlin/Heidelberg: Springer.

Ferretti, T. R., Kutas, M. \& McRae, K. (2007). Verb aspect and the activation of event knowledge. Fournal of Experimental Psychology: Learning Memory and Cognition 33(1), 182-196.

Flecken, M. (2011). What native speaker judgments tell us about the grammaticalization of a progressive aspectual marker in Dutch. Linguistics 49(3), 479-524.

Frick, R. W. (1998). A better stopping rule for conventional statistical tests. Behavior Research Methods, Instruments, छ० Computers 30(4), 690-697.

Gablasova, D., Brezina, V. \& McEnery, T. (2017). Collocations in corpus-based language learning research: identifying, comparing, and interpreting the evidence. Language Learning 67(S1), 155-179.

Graesser, A. C., Singer, M. \& Trabasso, T. (1994). Constructing inferences during narrative text comprehension. Psychological Review 101(3), 371-395.

Grice, H. P. (1975). Logic and conversation. In P. Cole \& J. L. Morgan (eds), Syntax and Semantics (Vol. 3, pp. 41-58). New York: Academic Press.

Gruber, J. S. (1976). Lexical structures in syntax and semantics. Amsterdam: North-Holland.

Hothorn, T., Bretz, F. \& Westfall, P. (2008). Simultaneous inference in general parametric models. Biometrical fournal 50(3), 346-363.

Jackendoff, R. (1991). Parts and boundaries. Cognition 41(1), 9-45.

Johnson-Laird, P. N. (1983). Mental models: towards a cognitive science of language, inference, and consciousness. Cambridge, MA: Harvard University Press.

Krifka, M. (1998). The origins of telicity. In S. Rothstein (ed.), Events and grammar (pp. 197-235). Dordrecht: Kluwer Academic.

Langacker, R. W. (1987). Foundations of cognitive grammar. Stanford, CA: Stanford University Press. 


\section{A STUDY OF NAAR AND RICHTING IN DUTCH}

Liao, Y., Flecken, M., Dijkstra, K. \& Zwaan, R. A. (2020). Going places in Dutch and mandarin Chinese: conceptualising the path of motion cross-linguistically. Language, Cognition and Neuroscience 35(4), 498-520.

Madden, C. J. \& Zwaan, R. A. (2003). How does verb aspect constrain event representations? Memory \& $^{\circ}$ Cognition 31(5), 663-672.

Magliano, J. P. \& Schleich, M. C. (2000). Verb aspect and situation models. Discourse Processes 29(2), 83-112.

Matlock, T. (2011). The conceptual motivation of aspect. In K.-U. Panther \& G. Radden (eds), Human cognitive processing (Vol. 27, pp. 133-148). Amsterdam: John Benjamins.

Norde, M. (2008). East Scandinavian på; a preposition of the 'third kind.' In K. Dekker, A. MacDonald \& H. Niebaum (eds), Northern voices: essays on Old Germanic and related topics offered to Professor Tette Hofstra (pp. 383-398). Leuven: Peeters.

Papafragou, A. \& Grigoroglou, M. (2019). The role of conceptualization during language production: evidence from event encoding. Language, Cognition and Neuroscience 34(9), 1117-1128.

Pinheiro, J., Bates, D., DebRoy, S., Sarkar, D. \& R Core Team (2019). nlme: linear and nonlinear mixed effects models. R package version 3.1-142. Online <https://CRAN.Rproject. org $/$ package $=$ nlme $>$.

Piñón, C. J. (1993). Paths and their names. In K. Beals, G. Cooke, D. Katman, S. Kita, K.-E. McCullough \& D. Testen (eds), Papers from the 29th Regional Meeting of the Chicago Linguistic Society (Vol. 2, pp. 287-303). Chicago: Chicago Linguistics Society.

R Core Team. (2016). R: a language and environment for statistical computing [Computer software]. Vienna, Austria: R Foundation for Statistical Computing. Online < https://www. R-project.org/>.

Radvansky, G. A. \& Zacks, J. M. (2014). Event cognition. New York: Oxford University Press.

Rychlý, P. (2008). A lexicographer-friendly association score. Masarykova Univerzita. Online $<$ https://www.muni.cz/en/research/publications/937193>.

van der Sijs, N. (2001). Chronological dictionary: the age and origin of our words and meanings (2nd ed). Amsterdam/Antwerp: Veen.

van Dijk, T. A. V. \& Kintsch, W. (1983). Strategies of discourse comprehension. New York: Academic Press.

Vandeloise, C. (2017). Three basic prepositions in French and in English: a comparison. Corela. Online <https://doi.org/10.4000/corela.5033>.

Vendler, Z. (1967). Linguistics in philosophy. Ithaca, NY: Cornell University Press.

Verkuyl, H. \& Zwarts, J. (1992). Time and space in conceptual and logical semantics: the notion of path. Linguistics 30(3), 483-512.

von Stutterheim, C., Carroll, M. \& Klein, W. (2009). New perspectives in analyzing aspectual distinctions across languages. In W. Klein \& P. Li (eds), The expression of time (pp. 195-216). Berlin/New York: Mouton de Gruyter.

Zacks, J. M. \& Swallow, K. M. (2007). Event segmentation. Current Directions in Psychological Science 16(2), 80-84.

Zhan, L. (2018). Scalar and ignorance inferences are both computed immediately upon encountering the sentential connective: the online processing of sentences with disjunction using the visual world paradigm. Frontiers in Psychology 9, 61, e2018.00061.

Zwaan, R. A. (2016). Situation models, mental simulations, and abstract concepts in discourse comprehension. Psychonomic Bulletin छ Review 23, 1028-1034.

Zwaan, R. A. \& Radvansky, G. A. (1998). Situation models in language comprehension and memory. Psychological Bulletin 123(2), 162-185.

Zwarts, J. \& Winter, Y. (2000). Vector space semantics: a model-theoretic analysis of locative prepositions. Fournal of Logic, Language, and Information 9, 169-211.

Zwarts, J. (2003). Vectors across spatial domains: from place to size, orientation, shape and parts. In E. van der Zee \& J. Slack (eds), Representing Direction in Language and Space (pp. 3968). Oxford: Oxford University Press.

Zwarts, J. (2005). Prepositional aspect and the algebra of paths. Linguistics and Philosophy 28(6), $739-779$.

Zwarts, J. (2008). Aspects of a typology of direction. In S. D. Rothstein (ed.), Linguistik Aktuell / Linguistics Today (Vol. 110, pp. 79-105). Amsterdam: John Benjamins. 


\section{Appendix I}

\section{Sentences used in Experiment 1}

\section{(1) GOAL-reached condition:}

1. de auto rijdt de tunnel in

2. de auto rijdt de wasstraat in

3. de bus rijdt de poort in

4. de bus rijdt de stad in

5. de jongen loopt de dierentuin in

6. de jongen loopt het huis in

7. de man loopt de kerk in

8. de man loopt het museum in

9. de vrachtwagen rijdt de parkeergarage in

10. de vrachtwagen rijdt het bos in

11. de vrouw loopt de winkel in

12. de vrouw loopt het ziekenhuis in

13. het busje rijdt de garage in

14. het busje rijdt het dorp in

15. het meisje loopt de flat in

16. het meisje loopt de speeltuin in 'the car drives into the tunnel' 'the car drives into the carwash' 'the bus drives into the gate' 'the bus drives into the city' 'the boy walks into the zoo' 'the boy walks into the house' 'the man walks into the church' 'the man walks into the museum' 'the truck drives into the parking lot' 'the truck drives into the wood' 'the woman walks into the store' 'the woman walks into the hospital' 'the van drives into the garage' 'the van drives into the village' 'the girl walks into the apartment' 'the girl walks into the playground'

\section{(2) Naar and richting conditions:}

1. de auto rijdt naar/richting de tunnel

2. de auto rijdt naar/richting de wasstraat

3. de bus rijdt naar/richting de poort

4. de bus rijdt naar/richting de stad

5. de jongen loopt naar/richting de dierentuin

6. de jongen loopt naar/richting het huis

7. de man loopt naar/richting de kerk

8. de man loopt naar/richting het museum

9. de vrachtwagen rijdt naar/richting de parkeergarage

10. de vrachtwagen rijdt naar/richting het bos

11. de vrouw loopt naar/richting de winkel

12. de vrouw loopt naar/richting het ziekenhuis

13. het busje rijdt naar/richting de garage

14. het busje rijdt naar/richting het dorp

15. het meisje loopt naar/richting de flat

16. het meisje loopt naar/richting de speeltuin 'the car drives to/towards the tunnel' 'the car drives to/towards the carwash' 'the bus drives to/towards the gate' 'the bus drives to/towards the city' 'the boy walks to/towards the zoo' 'the boy walks to/towards the house' 'the man walks to/towards the church' 'the man walks to/towards the museum' 'the truck drives to/towards the parking lot'

'the truck drives to/towards the wood' 'the woman walks to/towards the store' "the woman walks to/towards the hospital'

'the van drives to/towards the garage' 'the van drives to/towards the village' 'the girl walks to/towards the apartment' 'the girl walks to/towards the playground' 


\section{Appendix II}

Stimuli used in Experiment 2
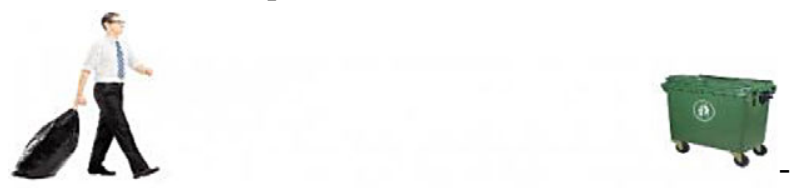

Hij loopt ( ? ) de container.

naar

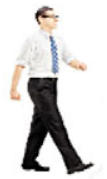

richting

Hij loopt ( ? ) de container.

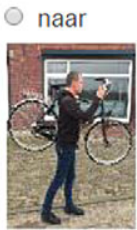

richting

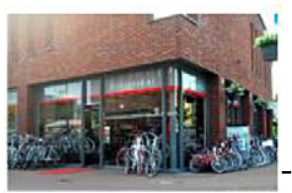

Hij loopt ( ? ) de fietsenmaker.

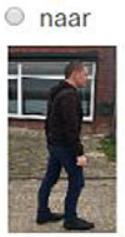

richting

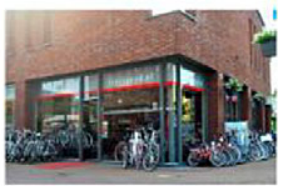

Hij loopt ( ? ) de fietsenmaker.

naar

richting 


\section{Appendix III}

Stimuli used in Experiment 3
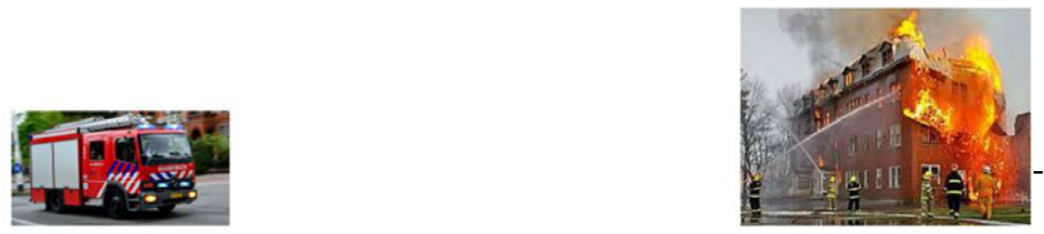

De brandweerauto rijdt ( ? ) het brandende gebouw.

naar

richting
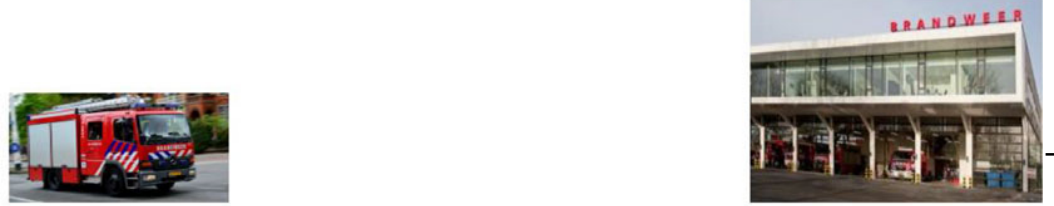

De brandweerauto rijdt (?) de brandweerkazerne.

naar

richting
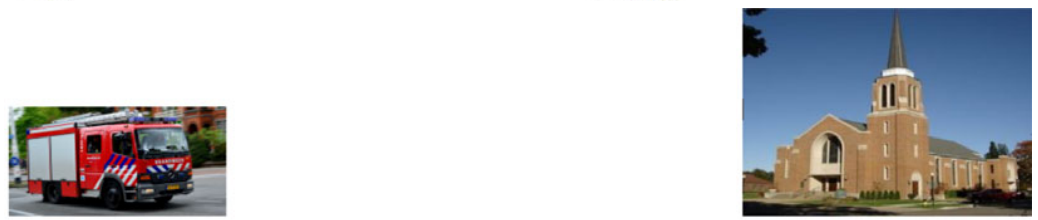

De brandweerauto rijdt (?) de kerk.

naar

richting 